Research Paper

\title{
Use of a sol-gel hybrid coating composed by a fluoropolymer and silica for the mitigation of mineral fouling in heat exchangers
}

\author{
Valeria Oldani, ${ }^{\text {a, } b, *}$ Gabriele Sergi, ${ }^{\text {a Carlo Pirola }},{ }^{\text {a, b }}$ Claudia L. Bianchi ${ }^{\text {a, b }}$ \\ a Dipartimento di Chimica, Università degli Studi di Milano, via C. Golgi 19, 20133 Milano, Italy

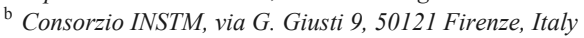

\section{A R T I C L E IN F O}

\section{Article history:}

Received 9 February 2016

Received in revised form 25 April 2016

Accepted 2 June 2016

Available online $\mathrm{xxx}$

\section{Keywords:}

Fouling

Heat exchangers

Hybrid coatings

Hydrophobicity

\section{Introduction}

Heat exchangers provide the perfect conditions for fouling; the heat exchanging fluids often contain dispersed or dissolved particles, which can adhere on the heat transfer surfaces, and the working temperatures are in general favourable for microorganism proliferation. The main effects of fouling in heat exchangers can be summarized as the increase of the overall heat transfer resistance and the increase of the pressure drop due to the reduction of the cross-sectional flow area, which means losses in the heat transfer efficiency [1,2]. Among all the possible techniques available for fouling control in heat exchangers, the use of metal surfaces, which do not suffer from deposition phenomena, would be certainly one of the best options [3]. To achieve this goal, an anti-fouling coating can be applied on the heat transfer surfaces. Many researches attest in particular the effectiveness of hydrophobic coatings on mitigation of crystallization fouling in heat exchangers [4-7]. Crystallization fouling is one of the most common types of fouling involving heat exchangers and consists in the precipitation and deposition of dissolved salts, after the supersaturation [8].

The preparation of anti-fouling coatings for application on heat transfer surfaces, however, is not trivial [9]. Beside the typical properties of mechanical, chemical and thermal stability, anti-fouling coatings for heat exchangers should not represent a further heat transfer resistance, hence their thickness have to be maintained lower than $5 \mu \mathrm{m}$ to ensure no insulator effects [3]. Moreover, the effect of the coatings on the average surface roughness should be controlled; the

\footnotetext{
* Corresponding author at: Università degli Studi di Milano, via G. Golgi 19, 20133 Milano, Italy.

Email address: valeria.oldani@unimi.it (V. Oldani)
}

average roughness of the heat transfer surface can in fact greatly influence the flow regime of the fluid in contact with the heat surface as well as the extent of the fouling phenomenon [10,11].

The organic/inorganic hybrid coating technology can contribute to the obtainment of an anti-fouling coating with the properties just discussed. The careful combination of an organic compound with an inorganic one permits in fact the obtainment of a composite material possessing both the typical properties of the two components [12].

Several reviews [13-15] attest the efficiency of the hybrid coating technology in the mitigation of bio-fouling. Even so, only few researches report the effects of the use of hybrid coatings in the mitigation of other types of fouling phenomena, such as mineral fouling, corrosion fouling or crude oil fouling, especially in heat transfer equipment. Cai et al. [16] studied a composite coating composed by titanium dioxide nanoparticles and fluoroalkylsilane, observing a lower fouling resistance in pool boiling saturated by $\mathrm{CaCO}_{3}$ in presence of the coating. Holberg and Bischoff [17] reported the application of hybrid coatings composed by an urea-siloxane systems. By the optimization of the synthesis, the authors obtained a mechanical robust hybrid coating with proven ability to repel crude-oil derived foulants on heat transfer surfaces.

In this research, we implemented an easy to handle procedure for the preparation of the coating, employing the well-known solgel synthetic technique. The procedure includes the co-condensation of tetraethyl orthosilicate, the precursor for silica coating preparation, with a triethoxysilane $\alpha, \omega$-substituted perfluoropolyether. This synthetic approach permits to intersperse homogeneously the inorganic phase $\left(\mathrm{SiO}_{2}\right)$ in the organic one, without compromising the typical properties of the polymer [18]. Hence, we obtained a stable hydrophobic coating based on the fluoropolymer [19] with enhanced thermal and mechanical stability conferred by the presence of the metal oxide, which possesses superior mechanical properties in re- 
spect to polymers [20]. The mechanical and chemical stability of the hybrid coating prepared in this work were investigated in liquid media, using chemically aggressive solutions and high temperatures to simulate the exposition to heat exchanging fluids. The anti-fouling properties, instead, were evaluated in a heat exchanger pilot plant, operating with water rich in carbonate salts responsible of crystallization fouling phenomena.

\section{Material and methods}

\subsection{Coatings synthesis and preparation}

The hybrid coating (briefly named $\mathrm{S} 10 / \mathrm{SiO}_{2}$ ) was prepared by combining a sol-gel silica coating and a perfluoropolyether derivative. The silica coating was prepared by classical sol-gel synthesis starting from the alkoxide precursor (TEOS), as reported by Kermadi et al. [21]. The commercial perfluoropolyether (named Fluorolink®S10, provided by Solvay Specialty Polymers) was mixed with TEOS, maintaining a weight ratio of 80/20 respectively, before the initiation of the hydrolysis and condensation reaction. iso-propanol was used as solvent in the sol-gel synthesis, the amount of solvent was maintained in large excess in order to reduce the viscosity of the sol-gel. The amount of S10 in respect to the solvent was $2.7 \mathrm{wt} \%$. Water was added in the molar ratio of 4.0/1.0 in respect to TEOS, and $\mathrm{pH}$ was regulated at a value of 2 using nitric acid. The sol-gel synthesis was performed at room temperature, maintaining the solution under stirring for $24 \mathrm{~h}$. The coatings were deposited on stainless steel substrates (plain samples of dimensions $30 \times 20 \mathrm{~mm}$ or tubes samples with internal diameter of $8 \mathrm{~mm}$ and length $100 \mathrm{~mm}$ ) via dip-coating. Namely, the substrates were kept immersed in the coating solution for $3 \mathrm{~h}$ and heat treated for $3 \mathrm{~h}$ at $383 \mathrm{~K}$ and for $1 \mathrm{~h}$ at $473 \mathrm{~K}$ in a static oven. Before the coating deposition, the stainless steel substrates were rinsed with water and acetone. Similarly, the tube bundle of the heat exchanger pilot plant was carefully washed with water and acetone and consequently dipped in the coating formulation (using a tank of $8 \mathrm{~L}$ volume) for $3 \mathrm{~h}$. The heat treatment was performed as previously described.

\subsection{Resistance and fouling tests}

The hybrid coating prepared was preliminary studied to assess its resistance when exposed to liquids simulating the heat exchanging fluids. Plain stainless steel substrates where used as samples for the resistance tests. The chemical stability was investigated by immersing the samples in a hydrochloric acid solution $(\mathrm{HCl}, \mathrm{pH}=2)$, a disinfectant solution containing chloramines $(\mathrm{pH}=7)$, and a synthetic seawater solution. During the tests, all the solutions were thermostated at a temperature of $323 \mathrm{~K}$. The thermal resistance was assessed by exposing the samples to water heated at $343 \mathrm{~K}$. The mechanical resistance was instead investigated by exposing the samples to a water flow, at a temperature of $323 \mathrm{~K}$, and velocity of $0.17 \mathrm{~m} / \mathrm{s}$. A similar test was performed using a solution of $\mathrm{CaSO}_{4}, 4 \mathrm{~g} / \mathrm{L}$ concentrated, instead of water. In that case, the $\mathrm{CaSO}_{4}$ solution, pre-heated at a temperature of $313 \mathrm{~K}$, was pumped (flowrate: $0.15 \mathrm{~m} / \mathrm{s}$ ) in a tubular stainless steel sample characterized by the presence of the coating on its internal surface. In such a way it was possible to assess the wear resistance of the coatings in presence of a solution rich in suspended particles. The apparatus used for the latter tests are described elsewhere [22]. All the resistance tests lasted for 30 days, apart from the test performed in presence of the $\mathrm{CaSO}_{4}$ solution, which lasted for 43 days. The testing liquids where replaced periodically every $2 / 3$ days, in order to maintain unaltered the environmental conditions to which the samples where exposed. The same resistance test was repeated at least two times, using different coated samples.
The deterioration of the coatings was monitored by measuring the water contact angle value of the coated substrates (Kruss Easydrop instrument). For each sample, at least 5 droplets where deposited on different position of the surface, and the CA value was calculated as the average of these measurements. A decrease in the CA value was representive of a deterioration of the coating.

The anti-fouling ability of the hybrid coating $\mathrm{S} 10 / \mathrm{SiO}_{2}$ was investigated on real heat transfer surfaces, by the aim of a heat exchanger pilot plant. The schematic of the plant is reported in Fig. 1.

The pilot plant is composed by two shell and tube heat exchangers (STHX), TEMA type NEW, working in parallel and designed identically. During the experimentation, only the tube bundle of STHX A was coated. Each heat exchanger is equipped with control devices (Table 1), which permitted the recording of the temperatures of the inlet and outlet fluids, in both shell side and tube side. The flowrates of the inlet fluids in shells and tubes were regulated using float flowmeters (see Table 1).

Table 2 reports in brief some specifications concerning the design of the two shell and tube heat exchangers.

Tap water, provided from the water system of the city of Milan, was used as operating fluid. The amount of calcium and magnesium measured in a sample of water corresponded to $76 \mathrm{mg} / \mathrm{L}$ and $18 \mathrm{mg} / \mathrm{L}$ respectively, therefore we supposed that the main fouling mechanism involved during the experiment was crystallization fouling. In fact, in a previous work, involving a similar apparatus working in analogous conditions, we clearly observed the formation of scale deposits on the

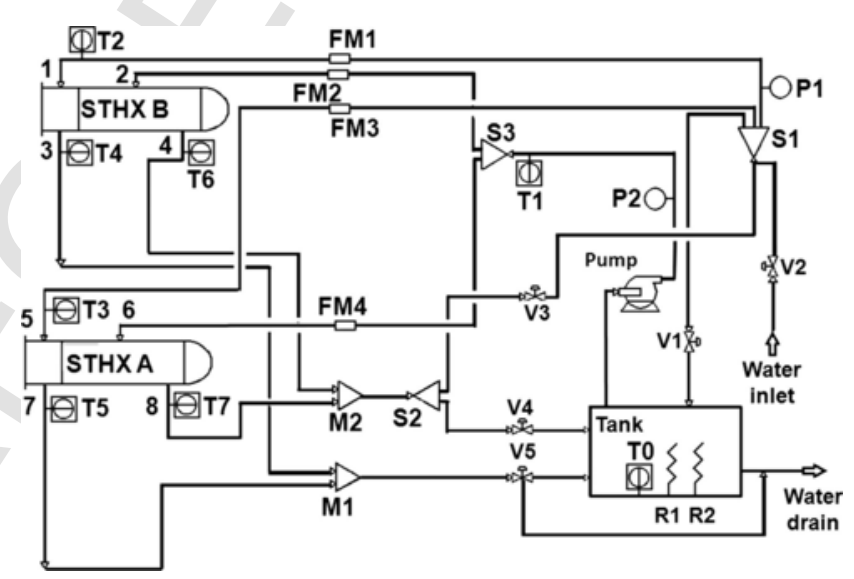

Fig. 1. Flowsheet of the heat exchanger pilot plant. STHX A, coated heat exchanger; STHX B, uncoated heat exchanger; FM, flowmeters; M, mixer; P, pressurimeters; R, heating elements; S, splitter; T, thermocouples; V, valves.

Table 1

Description of the operating units and of the analytical devices included in the heat exchanger pilot plant. The symbols adopted correspond to the ones reported in Fig. 1.

\begin{tabular}{|c|c|}
\hline $\begin{array}{l}\text { Symbol and } \\
\text { name }\end{array}$ & Specifications \\
\hline $\begin{array}{l}\text { FM1/FM2 float } \\
\text { flowmeter }\end{array}$ & $\begin{array}{l}\text { Parker, measure range: } 12-120 \mathrm{~L} / \mathrm{h} \text {, standard accuracy: } \pm 5 \% \text { of } \\
\text { full scale flow }\end{array}$ \\
\hline $\begin{array}{l}\text { FM3/FM4 float } \\
\text { flowmeter }\end{array}$ & $\begin{array}{l}\text { Key Instruments, measure range: } 120-1200 \mathrm{~L} / \mathrm{h} \text {, standard } \\
\text { accuracy: } \pm 5 \% \text { of full scale flow }\end{array}$ \\
\hline $\begin{array}{l}\mathrm{P} 1-\mathrm{P} 4 \\
\text { manometer }\end{array}$ & INOX, measure range: $0-5$ bar \\
\hline $\begin{array}{l}\mathrm{R} 1 / \mathrm{R} 2 \text { heating } \\
\text { elements }\end{array}$ & $230 \mathrm{~V}, 3 \mathrm{~kW}$, alimented in series \\
\hline $\begin{array}{l}\text { T0 } \\
\text { thermocouple }\end{array}$ & $\begin{array}{l}\text { Immersion thermocouple, rigid, for temperature measurement in } \\
\text { the hot water tank. Sensibility: } 10-50 \mu \mathrm{V} /{ }^{\circ} \mathrm{C}\end{array}$ \\
\hline $\begin{array}{l}\text { T1-T4 } \\
\text { thermocouples }\end{array}$ & Contact thermocouple, flexible, sensibility: $10-50 \mu \mathrm{V} /{ }^{\circ} \mathrm{C}$ \\
\hline V1-V6 valves & INOX ball valve, certified ISO 9001 and ISO 14001 \\
\hline
\end{tabular}


Table 2

Description of the shell and tube heat exchangers lay-out.

\begin{tabular}{|c|c|c|c|c|c|}
\hline \multicolumn{2}{|l|}{ Shell side } & \multicolumn{2}{|l|}{ Tube side } & \multicolumn{2}{|c|}{ Further specifications } \\
\hline $\begin{array}{l}\text { Internal } \\
\text { diameter }\end{array}$ & $90 \mathrm{~mm}$ & Number of tubes & 22 & $\begin{array}{l}\text { Baffles } \\
\text { cross }\end{array}$ & $\begin{array}{l}\text { Single } \\
\text { segmental }\end{array}$ \\
\hline $\begin{array}{l}\text { Outside } \\
\text { diameter }\end{array}$ & $102 \mathrm{~mm}$ & $\begin{array}{c}\text { Number of tubes } \\
\text { passes per shell }\end{array}$ & 6 & $\begin{array}{l}\text { Baffle } \\
\text { spacing }\end{array}$ & $27 \mathrm{~mm}$ \\
\hline Length & $700 \mathrm{~mm}$ & $\begin{array}{l}\text { Tubes internal } \\
\text { diameter }\end{array}$ & $8 \mathrm{~mm}$ & $\begin{array}{l}\text { Baffle } \\
\text { diameter }\end{array}$ & $87 \mathrm{~mm}$ \\
\hline $\begin{array}{l}\text { Number of } \\
\text { passes per } \\
\text { shell }\end{array}$ & 1 & Tubes length & $700 \mathrm{~mm}$ & $\begin{array}{l}\text { Flow } \\
\text { regime }\end{array}$ & $\begin{array}{l}\text { Counter } \\
\text { flow }\end{array}$ \\
\hline \multirow[t]{2}{*}{ Material } & Aluminium & Tubes layout & $30^{\circ}$ & & \\
\hline & & Material & AISI 316 & & \\
\hline
\end{tabular}

heat transfer surfaces [23]. The hot water, collected in the storage tank, was heated at a temperature of $313-323 \mathrm{~K}$ by two heating elements and consequently pumped inside the tubes at a flowrate of $720 \mathrm{~L} / \mathrm{h}$. The cold fluid, directly coming from the water supply network, flowed inside the shell at a temperature varying from $290 \mathrm{~K}$ to $292 \mathrm{~K}$ and flowrate $108-120 \mathrm{~L} / \mathrm{h}$.

We estimated the Re number in the shell side following the Kern method [24]; it ranged, during the operation, from 1880 to 2090. The Re number in the tube side was 2346; hence, the flow regime involved in the experimentation was mainly laminar. The operating conditions were kept very similar between the two heat exchangers during the experimental work, thus, it was possible to compare the heat transfer efficiency of the coated heat exchanger with the one of the uncoated heat exchanger. In the result section, the variation with time of the overall heat transfer coefficient $\left(U_{I m}\right)$ of STHX A is compared with the one of STHX B. The coefficient $U_{l m}$ was calculated according to Eq. (1) [25]:

$$
U_{l m}=\frac{Q}{A_{l m} \Delta T_{l m}}
$$

In Eq. (1), $Q$ is the quantity of heat transferred from the hot fluid to the cold one, $A_{l m}$ is the logarithmic mean of the heat transfer surface and $\Delta T_{l m}$ is the logarithmic mean of the temperature differences in the shell side and hot side.

Considering the formation of fouling layer prevalently on the internal side of the tubes, we also calculated the fouling resistance $R_{f}$, according to Eq. (2) [26]:

$$
R_{f}=\frac{1}{U_{t}}-\frac{1}{U_{0}}
$$

where $U_{t}$ is the overall heat transfer coefficient at the generic time $t$, while $U_{0}$ is the overall heat transfer coefficient at the start of the operation, i.e., when the heat transfer surfaces are supposed to be clean.

\section{Results and discussion}

\subsection{Chemical and mechanical resistance of the hybrid coatings}

Fig. 2 sums up the results of resistance tests. Here, the best results of each resistance tests are presented. The average CA value of a fresh coating deposited on the stainless steel substrate was $144^{\circ} \pm 3$. On the other hand, typically, a clean and uncoated stainless steel surface has a CA varying from $60^{\circ}$ to $80^{\circ}$. Therefore, the decrease in CA

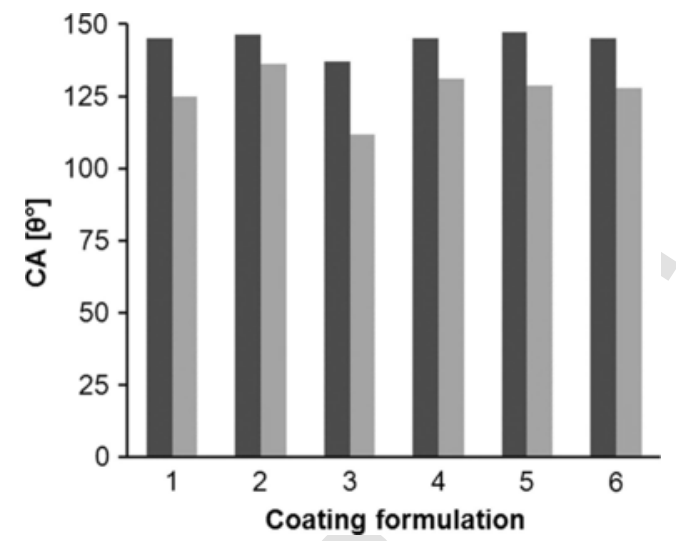

Fig. 2. Results of the resistance tests performed on the hybrid coating $\mathrm{S} 10 / \mathrm{SiO}_{2}$ : comparison between the CA measured before the test $(\square)$ and at the end of the test, lasted for 30 days $(\square)$. Exposition to: $1=\mathrm{HCl}$ solution, $2=$ disinfectant solution, $3=$ synthetic seawater solution, $4=$ water at $343 \mathrm{~K}, 5=$ water flux at $0.17 \mathrm{~m} / \mathrm{s}, 6=\mathrm{CaSO}_{4}$ solution fluxed in a coated tube at $0.15 \mathrm{~m} / \mathrm{s}$.

that we observed during the resistance tests was indicative of a progressive deterioration of the coating. The most detrimental solution for the hybrid coatings was represented by the synthetic seawater solution. After 30 days of immersion we observed a consistent decrease of CA ( $18 \%$ in respect to the starting value), corresponding to a final $\mathrm{CA}$ value of $112^{\circ}$. On the other hand, the exposition to the other typology of aggressive liquids did not alter consistently the wettability of the coated samples, and the final contact angles measured were always higher than $125^{\circ}$. Interestingly, the hybrid coating appeared highly stable against thermal stresses. The prolonged exposition to water at high temperature brought to a decrease in CA of only the $9 \%$. The hybrid coating demonstrated good mechanical resistance even against shear stresses; the exposition to the water flux and to the $\mathrm{CaSO}_{4}$ solution, fluxed inside the coated tube sample, determined a decrease in CA of the $12 \%$ (final contact angle $\sim 125^{\circ}$ ).

\subsection{Fouling mitigation}

The heat treatment necessary for the hardening of the hybrid coating was performed at high temperatures ( $383 \mathrm{~K}$ and $473 \mathrm{~K}$ ). We estimated a linear expansion of the stainless steel tubes due to the thermal gradient induced in the heating treatment of $0.1 \mathrm{~mm}$, which is a negligible value. From surface profilometry analyses (UBM Microfocus Measurement System), we estimated that the average thickness of the coatings that we prepared was $7 \mu \mathrm{m}$. Moreover, we observed an increase of the average roughness $(\mathrm{Ra})$ of the stainless steel substrate after the deposition of the coating from $0.749 \mu \mathrm{m}$ to $0.953 \mu \mathrm{m}$ (roughness was measured by profilometer analysis, UBM Microfocus Measurement System, on an area of $0.3 \times 0.5 \mathrm{~mm}$ and resolution of 500 points $/ \mathrm{mm}$ ).

The fouling mitigation effect of the hybrid coating can be observed comparing the overall heat transfer coefficient and the fouling resistance values calculated for the uncoated heat exchanger (STHX B), with the ones of the coated heat exchanger (STHX A), as presented in Figs. 3 and 4. The scattering of the experimental values observable in these figures is mainly due to the continuous variation of the temperatures and of the flowrates in the range reported in Section 2.2. The variation of these parameters involved simultaneously the two heat exchangers, which worked in parallel and in the same conditions for the whole duration of the experiment $(580 \mathrm{~h})$. Each $U_{l m}$ or $R_{f}$ value presented in Figs. 3 and 4 correspond to the average daily value, calculated from the data collected 8 times/day. 


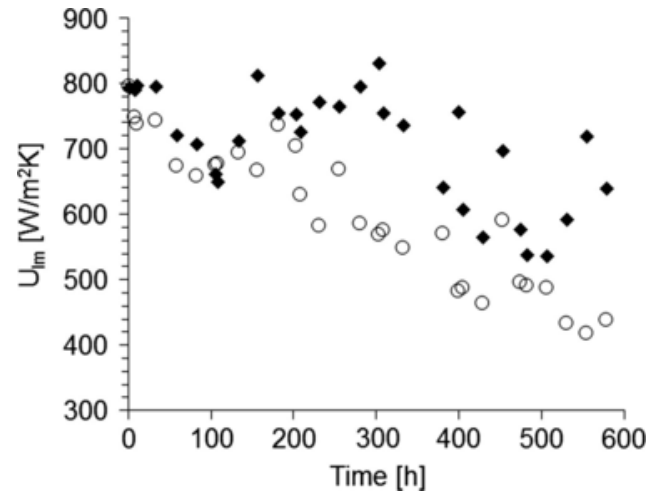

Fig. 3. Comparison between the values of the overall heat transfer coefficient $U$ of the coated heat exchanger STHX A $(\diamond)$ and the uncoated heat exchanger STHX B (O).

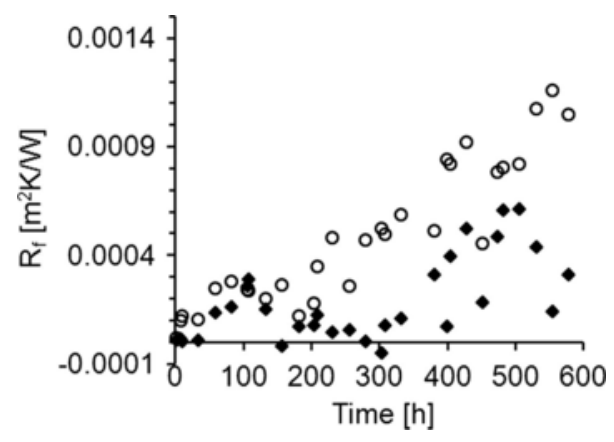

Fig. 4. Comparison between the fouling resistance $\left(R_{f}\right)$ values of the coated heat exchanger STHX A $(-)$ and the uncoated heat exchanger STHX B $(O)$.

Fig. 3 emphasizes the variation with time of $U_{l m}$ in STHX A and STHX B. The initial $U_{l m}$ values of STHX A and B were very similar, 793 and $795 \mathrm{~W} / \mathrm{m}^{2} \mathrm{~K}$ respectively, hence we can suppose that in the apparatus described, the influence of the hybrid coating on the heat transfer ability of the stainless steel surface was negligible. Until $200 \mathrm{~h}$ of operation the $U_{l m}$ value of STHX A and B remained almost similar. The average $U_{l m}$ value in the period $0-200 \mathrm{~h}$ for STHX A was $756 \mathrm{~W} / \mathrm{m}^{2} \mathrm{~K}$ and for STHX B $715 \mathrm{~W} / \mathrm{m}^{2} \mathrm{~K}$. After $200 \mathrm{~h}$ of operation, the overall heat transfer coefficient of STHX B started to decrease, while the $U_{l m}$ values of STHX A remained almost unvaried. The average value of $U_{l m}$ in the period comprised between 200 and $400 \mathrm{~h}$ was in fact $769 \mathrm{~W} / \mathrm{m}^{2} \mathrm{~K}$ for STHX A and $598 \mathrm{~W} / \mathrm{m}^{2} \mathrm{~K}$ for STHX B. Hence, a consistent decrease of the heat transfer capacity of the uncoated heat exchanger was observed after $200 \mathrm{~h}$ of operation. Hypothetically, the progressive reduction in the overall heat transfer coefficient observed in the uncoated heat exchanger was due to the formation of scale deposits on the heat transfer surfaces. On the other hand, the hydrophobic coating prevented the scale deposition on the heat transfer surfaces of STHX A until, at least, $400 \mathrm{~h}$ of operation. In fact, the $U_{l m}$ value of the coated heat exchanger decreased with a similar extent after $\sim 400 \mathrm{~h}$ of operation (During the working period of 400-550 h $U_{l m}$ was in fact $598 \mathrm{~W} / \mathrm{m}^{2} \mathrm{~K}$ ). At the same time, we observed that the overall heat transfer coefficient of the uncoated heat exchanger continued to decrease, the average value of $U_{l m}$ calculated from 400 to $550 \mathrm{~h}$ of operation was in fact $493 \mathrm{~W} / \mathrm{m}^{2} \mathrm{~K}$.

After $550 \mathrm{~h}$ of experiment, the pilot plant was shut down to permit the removal of the scale deposits formed on the heating units placed in the tank. The operation lasted for several hours and during that interval the two heat exchangers were completely emptied. After the maintenance procedure, the experimentation started again and proceeded for 80 more hours. During that period we observed a progres- sive restore of the initial $U_{l m}$ value in the coated heat exchanger (average $U_{l m}$ value in the period of operation $500-580 \mathrm{~h}$ was $687 \mathrm{~W} / \mathrm{m}^{2} \mathrm{~K}$ ). A similar result was not observed in the uncoated heat exchanger, the average $U_{l m}$ value in the same period was in fact $425 \mathrm{~W} / \mathrm{m}^{2} \mathrm{~K}$. The restoring of the initial heat transfer conditions observed in STHX A can be related to the hydrophobic/anti-fouling effect of the hybrid coating, which made difficult the adhesion of the foulant particles on the internal surfaces of the tubes. Hence, inducing wall shear stresses, the removal of the scale deposits was favored by the presence of the hybrid coating.

The assumptions made from the analyses of the $U_{l m}$ values in the two heat exchangers can be confirmed from the observation of the fouling resistance $\left(R_{f}\right)$ trends (Fig. 4).

The fouling resistance values remained very similar between the two heat transfer plants until $200 \mathrm{~h}$ of operation $\left(9 \cdot 10^{-5} v \mathrm{~s}\right.$ $1 \cdot 10^{-4} \mathrm{~m}^{2} \mathrm{~K} / \mathrm{W}$ for STHX A and B respectively). An increase of the $R_{f}$ value was observed for STHX B in the operating period comprised between 200 and $400 \mathrm{~h}$, in fact the average value rose at $4 \cdot 10^{-4} \mathrm{~m}^{2} \mathrm{~K} /$ $\mathrm{W}$. On the contrary, the fouling resistance remained almost unvaried for STHX A $\left(7 \cdot 10^{-5} \mathrm{~m}^{2} \mathrm{~K} / \mathrm{W}\right)$. Therefore, we can suppose a shift from the fouling induction period to the fouling period in the uncoated heat exchanger after $200 \mathrm{~h}$ of operation. A consistent rise of the fouling resistance in the coated heat exchanger was instead observed after $400 \mathrm{~h}$ of operation; the average $R_{f}$ value calculated between 400 and $500 \mathrm{~h}$ of working was in fact $5 \cdot 10^{-4} \mathrm{~m}^{2} \mathrm{~K} / \mathrm{W}$. Hence, the hydrophobic coating was able to prolong the fouling induction period of about $200 \mathrm{~h}$ in the conditions here adopted. Moreover, after the maintenance procedure, involving the shutdown of the pilot plant, we observed a decrease of the fouling resistance in the coated heat exchanger (the average value in the period of operation of $500-580 \mathrm{~h}$ was $2 \cdot 10^{-4} \mathrm{~m}^{2} \mathrm{~K}$ / W). This result can be explained by the removal of the fouling particles thanks to a wall shear stress effect, induced in the step of refilling of the heat exchanger. The same phenomenon was not observed on the uncoated heat exchanger, where the foulant particles had the possibility to adhere much strongly to the stainless steel surface. In fact, the average $R_{f}$ value in the last working period was $1 \cdot 10^{-3} \mathrm{~m}^{2} \mathrm{~K} / \mathrm{W}$.

\section{Conclusions}

We evaluated the applicability of a hybrid coating composed by a perfluoropolyether and a sol-gel silica network in fouling mitigation in heat exchangers. The synthetic procedure implemented involves an established technology for the industrial production of coatings, as the sol-gel procedure, and uses as raw material commercially available products, with the aim to scale-up such a technology. The main conclusions are the follow ones:

(1) The hybrid coating demonstrated the ability to reduce fouling due to scale on heat transfer surfaces. The fouling induction period was prolonged of about $200 \mathrm{~h}$ on coated heat transfer surfaces as evinced by the experimentation performed on a heat exchanger plant in pilot scale. Moreover, the coating improved the removal of the fouling deposits under wall shear stresses.

(2) The hybrid coating (having an average thickness of $7 \mu \mathrm{m}$ ) only scarcely affected the heat transfer ability of the stainless steel surfaces. However, we observed an increase of the average roughness of the stainless steel substrate of about $2.0 \mu \mathrm{m}$ after the deposition of the coating.

A selective study on the roughness variation, due to the coating deposition, on substrates having different Ra starting values, in respect to the one selected for this research, has not been performed yet. However, it is important to consider this effect in design step of the heat exchanger. 
(3) Such a results were obtained maintaining relative mild conditions in the pilot plant. Hard water was used as heat exchanging fluid, laminar flow conditions were maintained both in shell and tubes and small temperature differences $(\Delta \mathrm{T}=30 \mathrm{~K})$ occurred between the hot and cold fluid. For this reason, to obtain more precise results on the effectiveness of the $\mathrm{SiO}_{2} / \mathrm{S} 10$ hybrid coating in fouling mitigation, further investigations should be made varying the temperature ranges and the flow regimes, by adjusting the design of the heat exchanger pilot plant.

\section{Acknowledgments}

The work was partially financed by the project "Azione A del Dipartimento di Chimica per il Piano di Sostegno alla Ricerca - 2015/ 2017 - Linea 2" by the Dipartimento di Chimica, Università degli Studi di Milano.

\section{References}

[1] M. Markowski, M. Trafczynski, K. Urbaniec, Identification of the influence of fouling on the heat recovery in a network of shell and tube heat exchangers, Appl. Energy 102 (2013) 755-764.

[2] H. Müller-Steinhagen, M.R. Malayeri, P. Watkinson, Heat exchanger fouling: mitigation and cleaning strategies, Heat Transfer Eng. 32 (2011) 189-196.

[3] H. Müller-Steinhagen, Q. Zhao, Investigation of low fouling surface alloys made by ion implantation technology, Chem. Eng. Sci. 52 (1997) 3321-3332.

[4] A. Marmur, Super-hydrophobicity fundamentals: implications to biofouling prevention, Biofouling 22 (2006) 107-115.

[5] Q. Zhao, Y. Liu, C. Wang, S. Wang, H. Müller-Steinhagen, Effect of surface free energy on the adhesion of bio-fouling and crystalline fouling, Chem. Eng. Sci. 60 (2005) 4858-4865.

[6] Y.H. Cheng, H.Y. Chen, Z.C. Zhu, T.C. Jen, Y.X. Peng, Experimental study on the anti-fouling effects of NiCuP-PTFE deposit surface of heat exchangers, Appl. Therm. Eng. 68 (2014) 20-25.

[7] M. Förster, M. Bohnet, Modification of molecular interactions at the interface crystal/heat transfer surface to minimize heat exchanger fouling, Int. J. Therm. Sci. 39 (2000) 697-708

[8] S.N. Kazi, K.H. Teng, M.S. Zakaria, E. Sadeghinezhad, M.A. Bakar, Study of mineral fouling mitigation on heat exchanger surface, Desalination 367 (2015) $248-254$.
[9] D.J. Kukulka, P. Leising, Evaluation of heat exchanger surface coatings, Appl Therm. Eng. 30 (2010) 2333-2338.

[10] F. Albert, W. Augustin, S. Scholl, Roughness and constriction effects on heat transfer in crystallization fouling, Chem. Eng. Sci. 66 (2011) 499-509.

[11] A. Herz, M.R. Malayeri, H. Müller-Steinhagen, Fouling of roughened stainless steel surfaces during convective heat transfer to aqueous solutions, Energy Convers. Manage. 49 (2008) 3381-3386.

[12] H. Fischer, Polymer nanocomposites: from fundamental research to specific applications, Mater. Sci. Eng., C 23 (2003) 763-772.

[13] M. Lejars, A. Margaillan, C. Bressy, Fouling release coatings: a nontoxic alternative to biocidal antifouling coatings, Chem. Rev. 112 (2012) 4347-4390.

[14] Y. Tang, J.A. Finlay, G.L. Kowalke, A.E. Meyer, F.V. Bright, M.E. Callow, J.A. Callow, D.E. Wendt, M.R. Detty, Hybrid xerogel films as novel coatings for antifouling and fouling release, Biofouling 21 (2005) 59-71.

[15] J.A. Callow, M.E. Callow, Trends in the development of environmentally friendly fouling-resistant marine coatings, Nat. Commun. 244 (2011) 1-10.

[16] Y. Cai, M. Liu, L. Hui, $\mathrm{CaCO}_{3}$ fouling on microscale-nanoscale hydrophobic titania-fluoroalkylsilane films in pool boiling, AIChE J. 59 (2013) 2662-2678.

[17] S. Holberg, C. Bischoff, Application of a repellent urea-siloxane hybrid coating in the oil industry, Prog. Org. Coat. 77 (2014) 1591-1595.

[18] S. Pandey, S.B. Mishra, Sol-gel derived organic-inorganic hybrid materials: synthesis, characterizations and applications, J. Sol-Gel Sci. Techn. 59 (2011) 73-94.

[19] B. Ameduri, B. Boutevin, J.J.E. Moreau, H. Moutaabbid, M. Wong Chi Man, Hybrid organic \pm inorganic gels containing perfluoro-alkyl moieties, J. Fluorine Chem. 104 (2000) 185-194.

[20] J.D. Mackenzie, E.P. Bescher, Physical properties of sol-gel coatings, J. Sol-Gel Sci. Techn. 19 (2000) 23-29.

[21] S. Kermadi, N. Agoudjil, S. Sali, M. Boumaour, S. Bourgeois, M.C. Marco de Lucas, Sol-gel synthesis of $\mathrm{xTiO}_{2}(100-\mathrm{x}) \mathrm{SiO}_{2}$ nanocomposite thin films: structure, optical and antireflection properties, Thin Solid Films 564 (2014) $170-178$.

[22] V. Oldani, R. del Negro, C.L. Bianchi, R. Suriano, S. Turri, C. Pirola, B. Sacchi, Surface properties and anti-fouling assessment of coatings obtained from perfluoropolyethers and ceramic oxides nanopowders deposited on stainless steel, J. Fluorine Chem. 180 (2015) 7-14.

[23] V. Oldani, C.L. Bianchi, S. Biella, C. Pirola, G. Cattaneo, Perfluoropolyethers coatings design for fouling reduction on heat transfer stainless steel surfaces, Heat Transfer Eng. 37 (2016) 210-219.

[24] D.Q. Kern, Process Heat Transfer, International Student Edition, McGrow Hill International Book Company, Tokio, 1983.

[25] A. Dimian, C. Bildea, A. Kiss, Integrated Design and Simulation of Chemical Processes, second ed., Elsevier, Amsterdam, 2014.

[26] M.R. Malayeri, A. Al-Janabi, H. Müller-Steinhagen, Application of nano-modified surfaces for fouling mitigation, Int. J. Energy Res. 33 (2009) 1101-1113. 